\title{
ORIGEN DEL GERUNDIO
}

\author{
José María Jiménez Vásquez
}

In este artículo nos referiremos a la procedena il in forma verbal en -ndo, expresión de signo annumernistica del gerundio. Para ello trataremos de innimas, en la medida de nuestras posibilidades, anis remotos antecedentes $\mathrm{y}$, partiendo desde ain anercarnos poco a poco hasta las formas actuain Inestro gerundio. La finalidad de esta breve inmearigación es tratar de demostrar que el geruninini unineviso latino.

\section{Manifestaciones primitivas}

Según fuentes fidedignas, (1) la formación verinili en - ndo es una creación originaria de la rama rinica, pues no existen paralelos seguros de ella en nnus lenguas primitivas indoeuropeas. Es intereanne hacer notar que esta derivación se dio en los we principales dialectos del itálico: el osco, el mitro y el latín. A pesar del escaso conocimiento we se tiene de estos dos primeros, (2) existen alInasos ejemplos para ilustrar lo anterior:

\section{Insco: upsannam (3) (operandam), sakrannas (sacrandas).}

mbro: pihaner (4) (piandi), anferener (circumferendi).

Por lo que se respecta al latin, se sabe que el formativo -nd-, añadido al tema de presente, turo características morfo-sintácticas diversas y wariados significados.

\section{B. Formas latinas}

En cuanto a la forma de estos vocablos latinos, cabe observar que todos tienen un sufijo derirativo común, - nd-. A éste anteceden las vocales "a", "e" "u", por varias razones (temáticas, fonéticas, analógicas, etc.) y la siguen las posibles mar- cas numéricas, genéricas y casuales. Veamos primero las vocales antecedentes al'sufijo y luego los morfemas posteriores:

\section{Vocales temáticas y ligativas}

a. $-\mathrm{A}-\mathrm{ND}-$. La vocal "a" antecede al grupo -nd- cuando estos derivados pertenecen a verbos de la primera conjugación o de tema en "a": laudandus, amandus, ragandus.

b. $-\mathrm{E}-\mathrm{ND}-$. La "e" precede al derivativo -nd-por dos razones: porque la formación se hace con verbos de la segunda conjugación o de tema en $\overline{\mathrm{e}}$ : monendus, docendus, videndus, o porque se $\mathrm{da}$, en forma ligativa, entre el tema y el grupo -nd-, en las formaciones de verbos de la tercera (tema en consonante y en i) y en los de cuarta (tema en i): leg-e-ndus, capi-e-ndus, audi-e-ndus. Esta è ligativa es explicada por Ernout como influencia del sufijo derivativo del participio de presente en -ent-s: * volv-end-os, volvendus, frente a * volv-ent-s, volvens. (5)

c. -U-ND-. La "u" se halla antes de - nd-al lado de la "e" con verbos de la tercera y cuarta conjugación, pero se encuentra, sobre todo, en algunas formas arcaicas. Esta " $u$ " sale, según Tagliavini, de una antigua vocal temática " 0 " que formó con - nd-derivados en -ondos: (6) leg-u-ndus, scrib--u-ndus, ori-u-ndus.

Conviene destacar aquí que en latín existían también otras formaciones, que no se deben confundir con la anterior, terminadas en -bundus y -cundus (7): moribundus, plorabundus, vagabundus, iucundus, iracundus, fecundus, etc.

\section{Morfemas posteriores}

Los elementos morfemáticos que siguen al derivativo - nd- en latín son muchos. Consideramos que es suficiente esquematizarlos en un solo cuadro: 


\section{Singular}

$\begin{array}{llll} & \text { M. } & \text { F. } & \text { N. } \\ \text { N. } & - \text { us } & -a & -u m \\ \text { G. } & - \text { i } & -a e & -i \\ \text { D. } & -o & -a e & -o \\ \text { Ac. } & -u m & -a m & -u m \\ \text { Ab. } & -o & -a & -o\end{array}$

Plural

$\begin{array}{lll}\text { M. } & \text { F. } & \text { N. } \\ \text {-i } & \text {-ae } & \text {-a } \\ \text {-orum } & \text {-arum } & \text {-orum } \\ \text {-is } & \text {-is } & \text {-is } \\ \text {-os } & \text {-as } & \text {-a } \\ \text {-is } & \text {-is } & \text {-is }\end{array}$

\section{Valores de estas formas}

Examinemos ahora los valores que tienen estos derivados verbales latinos. Para ello propongamos algunos ejemplos literarios:

1. "Procul videnda est insula". (Ov., Met., $14,244)$.

2. “ $\mathrm{O}$ imprudentiam non ferendam!" (Cic., Ph., 2, 15).

3. "Virtutes omnibus discendae sunt semperque colendae". (Siegel, Conrado: Gramática latina, p. 304).

4. "Antigonus Eumenem mortuum propinquis eius sepeliendum tradidit". (Nep. 18, 13,4).

5. "Hannibal cum tradendus Romanis esset, venenum bibit". (Eutr., 4, 5).

6. "Sum cupidus te audiendi". (Cic., De orat., 2,4$)$.

7. "Ut nec triumviri accipiendo, nec scribae referendo sufficerent". (Liv., 36, 10).

8. "Cum ipse ad imperandum Tisidium vocaretur”. (Sall., J., 62. 8).

9. "Hominis mens discendo alitur et cogitando". (Cic., Off., 1, 105).

En los cinco primeros ejemplos, las formas verbales en estudio tienen carácter adjetival (concuerdan con su respectivo sustantivo en género, número y caso) y constituyen los llamados gerundivos, "participia necessitatis" o participios futuro-pasivos. Pueden denotar una simple idea de posibilidad, como los adjetivos en "-bilis" $\mathrm{dus}=\mathrm{amabilis}$, horrendus = horribilis, venerm dus = venerabilis, etc. Esto se observa en los $z^{2}$ minos "videnda" y "ferendam" de los ejempin uno y dos, respectivamente; pueden tambiên dicar obligación, deber o necesidad, como "discendas" y "colendas" del ejemplo tres; no tan algunos con expresión de finalidad o intenciót la que se capta en el "sepeliendum" del ejempit cuatro; además, dado el carácter esencialmentit pasivo que tienen, se juntan al verbo "esse" pan formar la llamada conjugación perifrástica pasita como en el "tradendus esset" del ejemplo cinco.

En los últimos cuatro ejemplos, los derivador verbales subrayados presentan carácter sustantivu $y$ forman el gerundio latino. Este se usa para decifnar el infinitivo de presente activo, supliendo a éste los casos que le faltan. Es un auténtico sas tantivo verbal neutro y se usa sólo en singular y er los siguientes casos: genitivo: "audiendi"; dativo: "accipiendo", "referendo"; acusativo con preposición: "ad imperandum"; ablativo solo o con preposición: "discendo, cogitando". Todos estos gerundios generalmente se traducen a nuestro idiome por infinitivos simples precedidos de preposición. exceptuando al ablativo solo:

$$
\begin{array}{ll}
\text { Remigandi labor. } & =\text { El trabajo de remar. } \\
\begin{array}{l}
\text { Aptus Discendo. } \\
\text { Parati ad }
\end{array} & \text { Apto para aprender. } \\
\begin{array}{l}
\text { audiendum. } \\
\text { Docendo }
\end{array} & =\text { Preparados para escuchar } . \\
\text { discitur. } & =\text { Se aprende enseñando. }
\end{array}
$$

\section{D. ¿Del gerundivo o del gerundio?}

Examinadas brevemente la forma y funciones de estos derivados verbales latinos, cabe ahora hacernos las siguientes preguntas: ¿Procede el gerundio español del gerundivo o del gerundio latino? Si procede del gerundio, ¿de cuál de sus casos?

Si comparamos las características morfo-sintácticas del gerundivo latino con las del gerundio español, fácilmente concluimos que es imposible que el primero haya originado al segundo. En efecto, nuestro gerundio es una especie de adverbio verbal, sin variaciones de género y número, sin expresión precisa de tiempo gramatical e incapaz de expresar por sí mismo idea de obligación, necesidad, deber o fìnalidad. En lo único que se pare- 
gerundio y el gerundivo latino es en el , común a los dos.

e apuntar aquí que nuestro idioma ha una cantidad considerable de sustantitivos provenientes de gerundivos latinos deben confundirse con los gerundios; ya diferente origen, distintos significado y además, son capaces de variaciones as de número y género. Unos de estos ter-ando y otros en -endo y, como cultisados directamente del latín, conservan en significación primitiva, hechas las conveexcepciones: expresan cualidades atribuiidea de futuro, como "reverendo, pudencrando, memorando, tremendo, horrendo, do", etc., o indican que el proceso verbal ejecutando o está por realizarse en alguna o cosa, e.g., "educando, graduando, doctoordenando, examinando"; en algunos casos stantivos cultos o populares que han perdido -ificado original, tal el caso de: "sumando, plicando, dividendo, hacienda, molienda, nda, ofrenda", etc.

Comparando, en cambio, el gerundio latino I español, hallamos varios puntos de contacto los dos: invariabilidad morfológica genérica y trica, indeterminación de persona y de tiempo uto, capacidad de admitir complementos y nodificado por adverbios, etc. Sin embargo, tramos una gran diferencia de significación el genitivo, dativo y acusativo del gerundio el nuestro: todos ellos, como sustitutivos finitivo de presente activo, equivalen a infisimples españoles y están regidos, generalpor adjetivos, sustantivos, verbos y prepo-

"Finines bellandi cupidi". (Caes., B. G., 1, 2, 4) $=$ Deseosos de guerrear.

cidem efforor studio patres vestros videndi". Sen., 23) $=$ Con el deseo de ver.

esse scribendo". = Estar presente para escribir. uedam loca eadem alia ad serendum idonea".

, R. R., 1, 23, 6) = Para sembrar.

quo pecuniam $o b$ absolvendum acceperis". Verr., 2, 2, 32) = Para absolver.

spoliandum corpus hostis". (Liv., 2,20) $=\mathrm{Al}$ ojar.

Como excepción, es posible traducir el gerunacusativo latino regido por "inter" con un gedio español; pero esto, sólo si se quiere llamar atención sobre la simultaneidad de dos hechos. a aclarar, transcribamos la oración completa:
"T. Herminius inter spoliandum corpus hostis veruto percussus est". = Despojando (o al despojar) $\mathrm{T}$. Herminio el cuerpo de un enemigo, fue herido por un dardo. Este uso, con todo, es sumamente raro en latín y no puede haber dado origen al gerundio español, pues éste nunca se usó con preposición "inter" en ninguna de las lenguas románicas. (8)

\section{E. Gerundio ablativo latino}

Examinemos a continuación el gerundio ablativo latino.

1. "Nomen invidae. . ductum est $a$ nimis intuendo fortunam alterius". (Cic., Tus., 2, 20) = de mirar.

2. "Summa voluptas ex discendo capitur". (Cic., Fam., 5, 18) = del aprender.

3. "Quid cogites de traseundo in Epirum scire sane velim". (Cic., Tus., 3, 20) = acerca de pasar. 4. "Multum in cogitando dolorem indipiscor". (P1., Trin., 224) $=$ pensando.

5. "Fit ut distrahatur in deliberando animus". (Cic., Off., 1, 3, 9) = deliberando.

6. "Hominis mens discendo alitur et cogitando". (Cic., Off., 1, 105) = aprendiendo y reflexionando.

7. "Erudiunt iuventutem venando, currendo". (Cic., Tus., 2, 14) = cazando, corriendo.

8. "Quis talia fando... temperet a lacrimis". (Verg., Aen., 2, 6) = diciendo.

9. "Multi patrimonia effuderunt inconsulte largiendo". (Cic., Off., 11, 54) = regalando.

De los ejemplos anteriores se pueden sacar las siguientes conclusiones:

1. Existió en latín un gerundio ablativo con preposición y otro sin ella. De los gerundios preposicionales sólo el que lleva "in" puede ser traducido por gerundio español; ya que indica expresión puntualizadora de simultaneidad. Este será el antecedente del gerundio con "en" español; los otros, al igual que los en genitivo, dativo y acusativo, se traducen con infinitivos simples con preposición. Los gerundios sin preposición, en cambio, se traducen todos al español por gerundios simples. 2. El gerundio ablativo apreposicional latino tenía varias funciones;

a) Una función básica, esencial, que se distingue por su significación instrumental -modal. En ella, el gerundio modifica-al verbo principal como en adverbio de medio o modo. Este es el carácter que poseen "discendo, cogitando, venando y currendo" de los ejemplos"seis y siete. 
b) Una función secundaria que sirve para expresar una acción concomitante que se desarrolla simultáneamente con la principal. Esto lo notamos con claridad en el "fando" del ejemplo ocho.

c) Una función sustitutiva o equivalente de participio de presente. En este caso el gerundio se refiere en forma equilibrada al sujeto y al verbo y designa también una acción secundaria realizada simultáneamente con la principal. Obsérvase esto en el "largiendo" del último ejemplo. Este gerundio podría muy bien conmutarse por el participio activo "largientes".

Estas funciones del gerundio apreposicional latino se dan plenamente en el español:

"Yo nunca he querido molestaros cantando". (J. R. Jiménez, Remordimiento).

"Y ella, dándome una rosa/me dijo: “ ¡Cuánto te quiero!" (J. R. Jiménez, Mañana de primavera). "¿La sangre? Yo vi más de un cazador / sobre su caballo, llevando el azor". (R. Darío, Los motivos del lobo).

\section{F. La terminación -0}

Nos queda todavia una cuestión por dilucidar: ¿Tomó nuestro gerundio la terminación "-o" del acusativo o del ablativo latino?

Si examinamos los textos más remotos del español, como los antiguos diplomas, las Glosas Emilianenses y las Closas Silenses, vamos a encontrar los auténticos gerundios terminados siempre en -o: "levando, sapiendo, stando, retornando, tradeçando, donando, faciendo, clamando". Aún más, hasta en casos donde esperamos otra termi- nación, hallamos -o: "ad confirmando ista Karts" 1046 Sahg. 506 ; "si aliquis homo ad disrumpend" ueneri” 1084 Sahg. 610'; "III galicos obtimos at confirmando illa cartula donationis" 1047 Sahe $506^{\circ}(9)$ Como se nota, hasta el acusativo vino a confundirse con el ablativo en su resultado fonés co.

Además, Heinrich Lausberg en su Lingüística Románica, tomo II, párrafo 817, presenta um cuadro sinóptico retroproyectivo que pone de menifiesto la mutua relación de la forma del gerundic ablativo con los gerundios de las lenguas románicas:

Según se observa en el cuadro, todos los gerundios románicos primitivos tuvieron su terminación en -o, aunque, con el correr del tiempo, algunos la perdieron. Actualmente se conserva en español, portugués, italiano y en algunos dialectos del sardo y desapareció en las otras lenguas romances: cantando (latín) = cantando (español, portugués, italiano y sardo), cantand (engadino), cantond (sobreselvano), chantant (francés), cantand (catalán), chantán (provenzal antiguo), cîntind (rumano) y cuntund (valaco).

Añádase a las dos razones anteriores, la opinión de algunas autoridades:

'Nous avons vu en parlant de l' infinitif que le gérondif a dû céder a ce mode dans toutes les fonctions dont il était chargé. Il a cependant conservé une de ses formes, l' ablatif; car la syntaxe démontre assez que l'it., esp. cantando, le fr. chantant procedent de ce cas et non d' un autre". (10)

\begin{tabular}{|c|c|c|c|}
\hline $1^{\circ}$ Conjugación & $2^{\circ}$ Conjugación & $3^{\circ}$ Conjugación & $4^{\circ}$ Conjugación \\
\hline $\begin{array}{l}\text {-ando } \\
\text {-ando (rum., } \\
\text { it., sar., } \\
\text { eng., fr., } \\
\text { sobres., prov., } \\
\text { cat., esp. y } \\
\text { port.) }\end{array}$ & $\begin{array}{l}\text {-ando } \\
\text {-ando (rum., } \\
\text { eng. y fr.) }\end{array}$ & $\begin{array}{l}\text {-endo / -iendo } \\
\text {-ando (rum., } \\
\text { eng. y fr.) }\end{array}$ & $\begin{array}{l}\text {-iendo } \\
\text {-ando (fr.) }\end{array}$ \\
\hline $\begin{array}{l}\text {-endo (dialec- } \\
\text { tos it. Y sar.) }\end{array}$ & $\begin{array}{l}\text {-endo (it., } \\
\text { sar., sobres, } \\
\text { prov., cat., } \\
\text { esp. y port.) }\end{array}$ & $\begin{array}{l}\text {-endo (it., } \\
\text { sar., sobres., } \\
\text { prov., cat., } \\
\text { esp. y port.) }\end{array}$ & $\begin{array}{l}\text {-endo (it., sar., } \\
\text { sobres., prov. y } \\
\text { esp.) }\end{array}$ \\
\hline & -i-ando (rum.) & -i-ando (rum.) & \\
\hline
\end{tabular}


- = girondif est par sa forme un ablatif et par sa =urnt du participe latin de durée". (11)

- La forma del gerundio castellano es enteramente I-il a la del ablativo del gerundio latino, v.gr. In - -ndo = ama -ndo. Si procede del ablativo, la Inta de aquel caso era igual al tema. Este es el - sufijo formativo de gerundios y con él sólo y =clusivamente se forman". (12)

Parece que Menéndez Pidal hace provenir el zerundio español del gerundio acusativo latino, nno se puede colegir de la siguiente expresión:

El gerundio y participio de presente tienen igual macal tónica y protónica: cantandum cantando, timendum temiendo, dormiendum durmiendo". (13)

Con todo, no lo dice abiertamente ni mucho menos lo demuestra.

No encontramos, por tanto, ninguna razón de peso que nos haga creer que la -o final de nuestro gerundio tenga que proceder de la desinencia -um del acusativo; antes al contrario, históricamente queda demostrado que procede directamente de la desinencia casual del gerundio ablativo latino.

En conclusión, nuestro gerundio simple español es, por razones morfológicas, sintácticas, semánticas e históricas, un trasplante directo del gerundio ablativo latino solo o con "in".
Tagliavini, Carlo: Fonética e morfología storica del latino, pp. 230-232.

Del osco y del umbro sólo quedan algunas inscripciones y unos pocos datos aislados de gramáticos y lexicógrafos.

Acerca de la asimilación de "nd" en " $n$ " en el osco y el umbro, vid. Stolz, F.: Historia de la lengua latina, p. 37.

Acerca del genitivo latino en -i y del genitivo umbro en -eis, -es, -er, vid. Tagliavini, Carlo: op Cit., p. 37.

Ernout, A. y Thomas, F.: Syntaxe latine, p. 262.

Tagliavini, Carlo: op. cit., p. 231.

Ernout, A.: Morphologie historique du latin, p. 174.
(8) Cfr. Lausberg, H.: Lingüistica Románica, T. II, párrafo 821.

(9) Menéndez Pidal, R.: Orígenes del español, párrafo 72,4 .

(10) Diez, Federico: Grammaire des langues romanes, t. III, p. 237.

(11) M eyer-Lübke: Grammaire des langues romanes, $t$. III, p. 556.

(12) Lanchetas, Rufino: Morfología del verbo castellano, p. 47.

(13) Menéndez Pidal, R.: Manual de gramática histórica española, párrafo 115,4, p. 301.

\section{BIBLIOGRAFIA}

Allen and Greenough's: New latin gramar, Gin and company, propietors, Boston, 1903.

Baldinger Kurt: La formación de los dominios lingüisticos en la Península Ibérica, Gredos, S. A., Madrid, 1963.

Diez, Federico: Grammaire des languesromanes, t. III, F. Vieweg, libraire-éditeur, Paris, 1876.

Ernout, Alfred: Morpholigie historique du latin, 3eme. édition revue et corrigée, Klinsksieck, París, 1974.
Ernout, A. et Thomas, F.: Syntaxe latine, 2 eme. édition, Klinsksieck, París, 1953.

Errandonea, Ignacio: Gramática latina, 6a. ed., Eugenio Subirane, editor pontificio, Barcelona, 1930.

Franchella, Quirino: Gramática latino-castellana, Universidad Nacional de Tucumán, Tucumán, 1951.

García de Diego, Vicente: Gramática histórica española, Gredos, S. A.; Madrid, 1951. 
Grandgent, C. H.: Latin vulgar, Publicaciones de la Revista de Filología, Madrid, 1928.

Hansen, Federico: Gramática histórica de la lengua castellana, Halle, S. A., Max Niemeyer, 1913.

Lanchetas, Rufino: Morfologia del verbo castellano, Bailly Bailliere, Madrid, 1987.

Laurant, L. et Lauras, A.: Manuel des études grecques et latines, II, Rome, 13 eme. édition, A. et J. Picard et Cie., Paris, 1960.

Lausberg, Heinrich: Lingüistica Románica, II, Gredos, S.A., Madrid, 1966.

Menéndez Pidal, R.: Cantar de Mio Cid, texto, gramática y vocabulario, V. I, 3a. ed., Espasa Calpe, S. A., Madrid, 1954.

: Manual de gramática histórica española, 14a. ed., Espasa-Calpe, S. A., Madrid, 1973.

: Orígenes del Español, 6a. ed., EspasaCalpe, S.A., Madrid, 1968.

Meyer-Lübke: Grammaire des langues romanes, t. III, Syntaxe, H. Welter, Editeur, Paris, 1895.

Nebrija, Elio Antonio de: Grmática castellana, edición de Galindo Romeo y Ortiz Muñoz, Madrid, 1946.

Padilla Salvador: Gramática histórico-critica de la lengua española, 6a ed., Sáenz de Jubera Hermanos, Madrid, 1912.

Palmer, L. R.: The latin language, Faber and Faber limited, London, 1974.

Rohlfs, Gerhard: Manual de filologia hispánica, Instituto Caro y Cuervo, Bogotá, 1957.
Sermo vulgaris latinus, Tubingen, Niemeyer, 1969.

Siegel, Conrado: Gramática latina, 4a. ed., Editarmin Guadalupe, Buenos Aires, 1960.

Stolz, Friedrich: Historia de la lengua latina, Utehtm México, 1961.

Strecker, Karl: Introduction to medieval latin, translation and revision by Robert B. Palmer Dublin, 1971.

Tagliavini, Carlo: Fonética e morfologia storica del latin: 3. ed. riveduta e aggiornata, $\mathrm{R}$. Patron, Bologna 1962.

Tempini, Octavio: Gramática latina, Edit. Don Boscon. Buenos Aires, 1951.

Tittarelli, Enrico: Gramática latina, Societá Editrice Internazionale, Torino, 1947.

Torres y Gómez, Manuel E.: Gramática histórico-comparada de la lengua castellana, Sáenz de Jubera Her manos, Madrid, 1899.

Tovar, Antonio: Gramática histórica latina, Afrodisio Aguado, S. A., Madrid, 1946.

Väänänen, Veiko: Introducción al latín vulgar, Gredos, S. A., Madrid, 1971.

Valentí Fiol, E.: Sintaxis latina, 9a. ed., Bosch, Barcelona, 1960.

Zenoni, Giovanni: La sintassi latina, Edizioni Zenoni, Venezia, s. f. 